\title{
Seasonal characteristics of future climate change over Japan and the associated atmospheric circulation anomalies in global model experiments
}

\author{
Rui Ito ${ }^{1,2}$, Tomoaki Ose ${ }^{2}$, Hirokazu Endo ${ }^{2}$, Ryo Mizuta ${ }^{2}$, Kohei Yoshida ${ }^{2}$, Akio Kitoh ${ }^{1,2}$ \\ and Tosiyuki Nakaegawa ${ }^{2}$ \\ ${ }^{1}$ Japan Meteorological Business Support Center, Japan \\ ${ }_{2}^{2}$ Meteorological Research Institute, Japan Meteorological Agency, Japan
}

\begin{abstract}
:
Information on future climate change considering regional characteristics is necessary to establish adaptation strategies for global warming. We investigated the seasonal characteristics of future climate projections over Japan and surroundings (JPN) in the late 21 st century, focusing especially on the source of uncertainty, based on two ensembles of the Coupled Model Intercomparison Project Phase 5 (CMIP5) and the Meteorological Research Institute atmospheric general circulation model (MRI-AGCM) global warming simulations. The ensemble mean surface air temperature increase over JPN is lower than that over the East Asian land region (EAS), reflecting the continent-ocean contrast, whereas quantitative changes in future precipitation depend on the ensembles. The CMIP5 mean atmospheric circulation around JPN weakens in winter and summer, while the future seasonal march tends to be delayed in the northern part of JPN during spring and autumn. Significant CMIP5 inter-model correlations are detected between the JPN climate projections and future circulation anomalies - e.g. the ensemble members simulating the westerly/ southeasterly wind anomaly tend to project hotter/wetter future summers. The high-resolution MRI-AGCM projection is consistent with the CMIP5 inter-model correlations when the future change in typhoon-associated precipitation is removed, indicating typhoon simulations can substantially influence future projections.
\end{abstract}

KEYWORDS global warming; Japan; East Asia; sea-level pressure; typhoon; CMIP5

\section{INTRODUCTION}

To design an adaptation strategy for future global warming in Japan, detailed analyses of climate change specific to Japan are required. Understanding the source and extent of uncertainty is also important in order to utilize the analyses properly. The Coupled Model Intercomparison Project (CMIP) has provided simulations of possible future changes, which are useful as an ensemble of opportunity for understanding uncertainty (Knutti et al., 2010).

Global warming will lead to greater warming over land than over oceans. This uneven warming consequently changes atmospheric circulation, which also modifies regional features, especially spatial patterns in precipitation change (Xie et al., 2015). Therefore, the Intergovernmental Panel on Climate Change (IPCC) assessment reports have divided the globe into 20 or more land regions (IPCC, 2012, 2013). Among these regions, Japan is classified as part of the East Asian land region (EAS); however, future climate change over Japan, surrounded by the sea, may be somewhat different from that over other parts of EAS, which mostly consists of continental land. Therefore, information on future projections for EAS may not be appropriate for Japan.

According to CMIP multi-model analysis, future summer precipitation in East Asia will generally increase, mainly due to an increase in atmospheric moisture (Endo and Kitoh, 2014). However, the spatial pattern in precipitation change is significantly influenced by the atmospheric circulation in summer (He and Zhou, 2015; Horinouchi et al., 2019; Ose, 2019) and in winter (Kimoto, 2005; Ogata et al., 2014).

The CMIP multi-model ensemble (MME) is useful to discuss uncertainty but is not sufficient to investigate climate changes at a regional scale such around Japan. Typically, the 200-km resolution of the CMIP Phase 5 (CMIP5; Taylor et al., 2012) models is too low to capture small-scale details of regional climates or to resolve tropical cyclone (TC) or typhoon behavior. In contrast, the Meteorological Research Institute atmospheric general circulation model, with 20-km horizontal resolution (MRI-AGCM20; Mizuta et al., 2012), can reproduce such detailed climatology and TCs more realistically, in particular in terms of the TCs that have a large impact on extreme precipitation over Japan (Kitoh and Endo, 2016, 2019; Endo et al., 2017; Yoshida et al., 2017).

The purpose of this study is firstly to identify the seasonal characteristics of climate change over Japan using the CMIP5 MME and the MRI-AGCM20 ensemble, paying attention to differences in future changes between the Japan and its surroundings (JPN) and EAS. Secondly, using the diversity of projections provided by the CMIP5 ensemble members, we explore how the uncertainty in future changes in temperature and precipitation relates to atmospheric circulation changes. The projections with MRI-AGCM20 are also subject to atmospheric circulation changes on a large 
scale as simulated in the low-resolution models of CMIP5; thus, it is worth comparing the two ensembles in terms of atmospheric circulation changes.

\section{METHODOLOGY}

We analyzed the global climate simulations of the CMIP5 MME. Outputs from historical experiments (1980 1999) and the Representative Concentration Pathway 2.6 (RCP2.6) and RCP8.5 experiments (2076-2095) were investigated. The CMIP5 models used are listed in Table SI. We used four indices: seasonal averages of mean surface air temperature (Tav) and mean precipitation (Pav), as well as the seasonal maximum 1-day precipitation total (Rx1d) and the number of summer days (SU, daily maximum temperature $>25^{\circ} \mathrm{C}$ ). We obtained the dataset for Rxld from the website http://etccdi.pacificclimate.org (Sillmann et al., 2013a, 2013b). Other indices were calculated based on the monthly output for Tav and Pav and the daily-maximum output for SU. These indices were first calculated on the models' native grid-cells and then the 20 -year averages were interpolated onto the grid-cells of MRI-AGCM20.

Future projections with MRI-AGCM20 were analyzed for the same periods. The experimental data consisted of a single member for the historical run and four members with different patterns of changing sea surface temperature (SST) for each future scenario run. The method of creating the future SST data is described by Mizuta et al. (2014), and details on simulations under RCP8.5 are set out by Kitoh and Endo (2016).

The area analyzed is shown in Figure 1. The area of EAS, consisting of land grid-cells only, is identical to that in previous IPCC reports (IPCC, 2012, 2013). In addition, we defined the JPN area to identify climate change around Japan, including both land and sea grid-cells.

Sea-level pressure (SLP) was used as a representative future change in atmospheric circulation around JPN by defining westerly and southerly wind change indices based on the sea-level geostrophic wind. The westerly change index $\left(\Delta \mathrm{U}_{\text {index }} ; \mathrm{hPa}\right)$ around JPN is defined as follows:

$$
\Delta \mathrm{U}_{\text {index }}=-\left(\Delta \mathrm{SLP}_{45^{\circ} \mathrm{N}}-\Delta \mathrm{SLP}_{25^{\circ} \mathrm{N}}\right)
$$

where $\Delta \operatorname{SLP}_{\varphi}(\mathrm{hPa})$ is the longitudinally averaged future change in SLP at latitude $\varphi$ along $120^{\circ} \mathrm{E}-150^{\circ} \mathrm{E}$. The southerly wind change index $\left(\Delta \mathrm{V}_{\text {index }} ; \mathrm{hPa}\right)$ is defined using

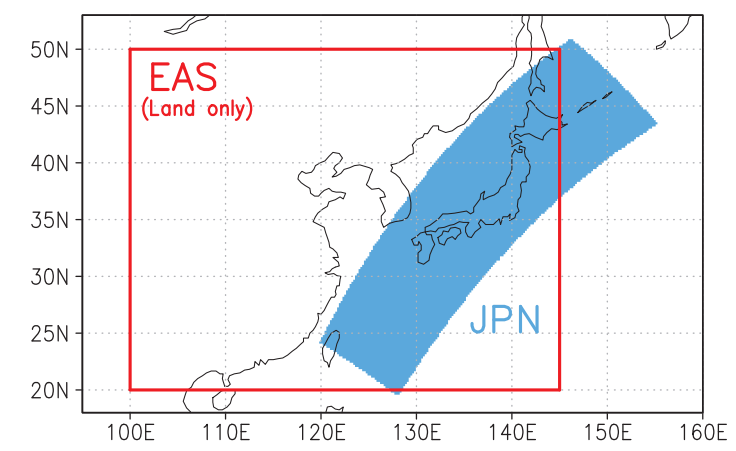

Figure 1. Definition of the study areas the latitudinally averaged future change in SLP at longitude $\lambda$ along $25^{\circ} \mathrm{N}-45^{\circ} \mathrm{N}$ as $\triangle \mathrm{SLP}_{\lambda}$ :

$$
\Delta \mathrm{V}_{\text {index }}=\Delta \mathrm{SLP}_{150^{\circ} \mathrm{E}}-\Delta \mathrm{SLP}_{120^{\circ} \mathrm{E}}
$$

Note that $\Delta \mathrm{U}_{\text {index }}$ and $\Delta \mathrm{V}_{\text {index }}$ represent the change in the mean sea-level geostrophic wind around JPN; they do not include details of surface winds over land or the effects of topography. The specific relationships between the indices and the sea-level geostrophic wind change is described in Text S1.

To assess the effects of TCs on future changes projected by MRI-AGCM20, precipitation associated with TCs was obtained following Kitoh and Endo (2016), where precipitation within a $500-\mathrm{km}$ radius of the TC center is regarded as TC-associated precipitation.

All projection values were scaled through all seasons and all spatial grids by $3.6 \mathrm{~K}(1.2 \mathrm{~K})$ warming, which corresponds to the CMIP5 MME mean of the global annual mean temperature increments under RCP8.5 (RCP2.6). These scaling factors were adopted to remove the intermodel differences in global climate sensitivity.

\section{RESULTS} Comparison of climate changes between EAS and
JPN

Figure 2 illustrates the future change in mean temperature $(\triangle \mathrm{Tav})$ over EAS and JPN under the RCP8.5 and RCP2.6 scenarios (shown without scaling in Figure S1).
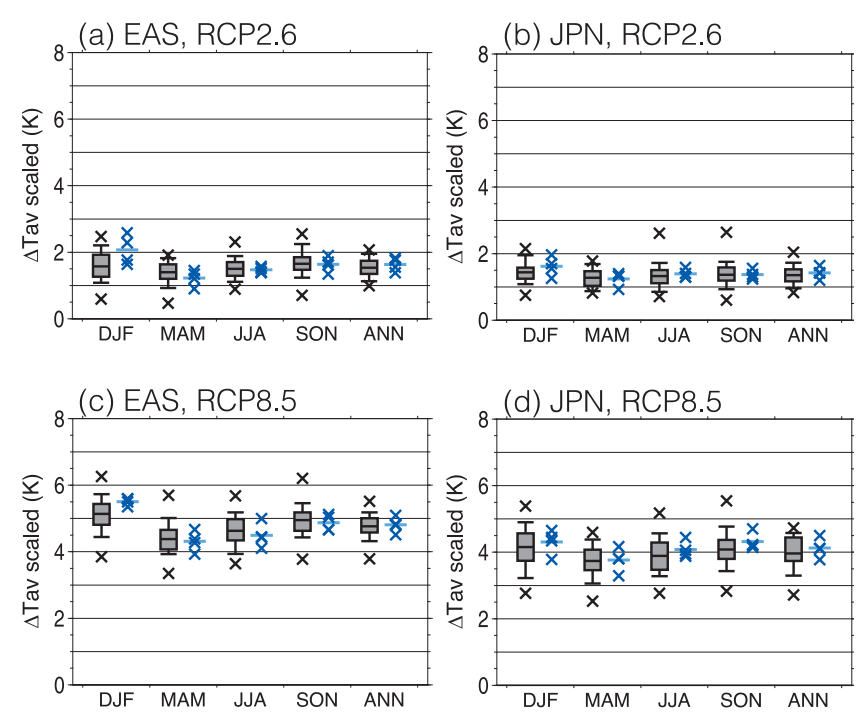

Figure 2. Mean temperature change in (a, c) EAS and (b, d) JPN under $(\mathrm{a}, \mathrm{b})$ the RCP2.6 and (c, d) RCP8.5 scenarios scaled to the CMIP5 MME mean of global annual temperature increment under each scenario. CMIP5 model projections are indicated by box-and-whisker plots (10\%, 25\%, mean, $75 \%$, and $90 \%$ ) and crosses (minimum and maximum). MRI-AGCM20 projections are shown by blue crosses (bars) for each member (ensemble mean). Note that one CMIP5 model, FIO-ESM, is excluded in RCP2.6 because the global temperature increase is small, with a negative value in DJF, as in IPCC (2013) 
For the CMIP5 projections, the ensemble mean of the annual change is $4.8 \mathrm{~K}(1.5 \mathrm{~K})$ over EAS and $4.0 \mathrm{~K}(1.4 \mathrm{~K})$ over JPN under RCP8.5 (RCP2.6), thus showing a smaller increase over JPN than over EAS. The same tendency was found for the seasonal values and for the MRI-AGCM20 projections. This is because the continental land warms faster than the sea surrounding JPN under enhanced greenhouse forcing (IPCC, 2013). A smaller increase in MarchMay (MAM) relative to the other seasons over both areas was also noted.

Future changes in mean precipitation $(\triangle \mathrm{Pav})$ and annual or seasonal maximums of 1-day precipitation total $(\Delta \mathrm{R} \times 1 \mathrm{~d})$ are shown in Figure 3 (shown without scaling in Figure S2). Over EAS, most CMIP5 models project an increase in Pav and Rx1d for all seasons, and the rates of increase were generally higher for Rx1d than for Pav (Figure 3a-d). $\triangle \mathrm{Pav}$ for the CMIP5 MME mean was $10.9 \%$ (5.5\%) for the annual mean under RCP8.5 (RCP2.6), while $\triangle \mathrm{Rx} 1 \mathrm{~d}$ was $25.6 \%(8.6 \%)$. However, there is large uncertainty in the (a) EAS, RCP2.6, Pav

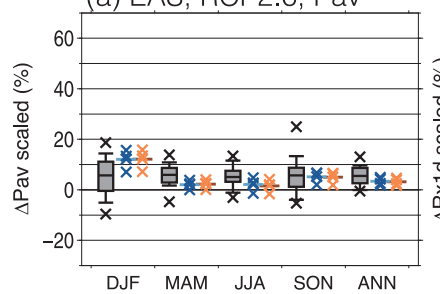

(c) EAS, RCP8.5, Pav

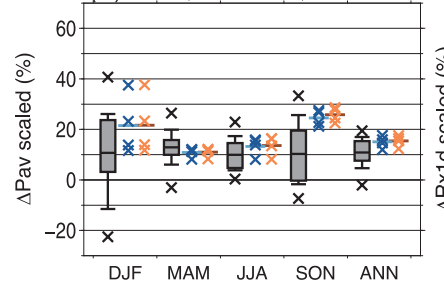

(e) JPN, RCP2.6, Pav

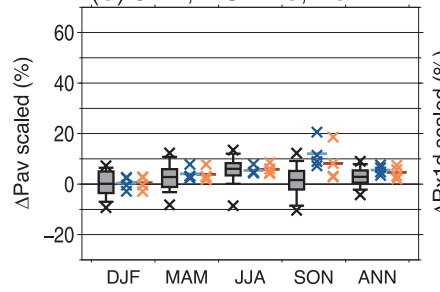

(g) JPN, RCP8.5, Pav

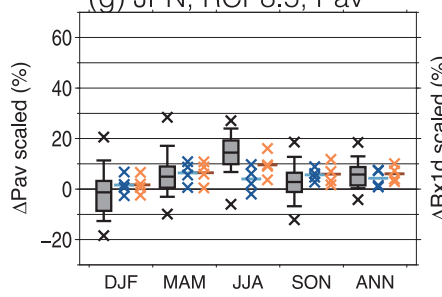

(b) EAS, RCP2.6, Rx1d

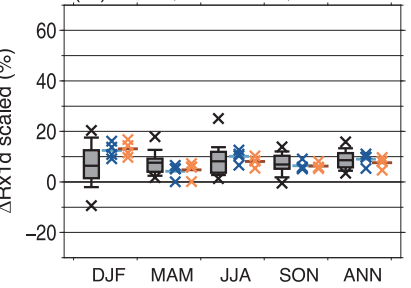

(d) EAS, RCP8.5, Rx1d

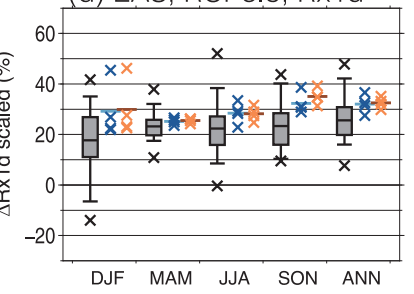

(f) JPN, RCP2.6, Rx1d

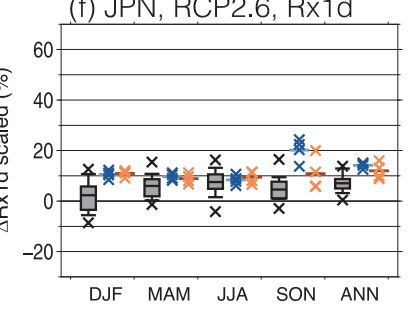

(h) JPN, RCP8.5, Rx1d

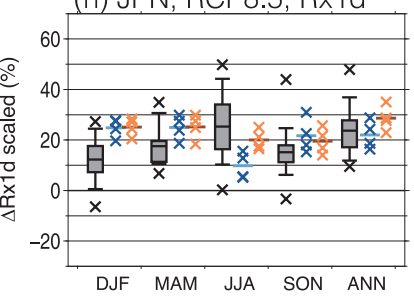

Figure 3. Same as Figure 2, but for (a, c, e, g) mean precipitation and $(b, d, f, h)$ annual or seasonal maximum of 1-day precipitation total. Changes in the precipitation indices excluding TC-associated precipitation with MRI-AGCM20 are also shown by the orange bars and crosses magnitudes of $\triangle \mathrm{Pav}$ and $\Delta \mathrm{Rx} 1 \mathrm{~d}$. Over JPN, $\Delta \mathrm{Pav}$ was smaller and the sign of the change was more uncertain than over EAS, except for June-August (JJA) when the rate of increase exceeded that over EAS (Figures $3 \mathrm{e}, \mathrm{g}$ ). $\Delta \mathrm{Rx} 1 \mathrm{~d}$ over JPN was comparable to that over EAS, and had a positive sign in more than $90 \%$ of the CMIP5 models for most seasons. $\triangle \mathrm{Pav}$ for the CMIP5 MME mean was 5.8\% (2.9\%) for the annual mean under RCP8.5 (RCP2.6), while $\triangle \mathrm{Rx} 1 \mathrm{~d}$ was $23.7 \%(7.1 \%)$. Note that the annual $\Delta \mathrm{Rx} 1 \mathrm{~d}$ values are approximately proportional to the global-mean temperature increments in the scenarios, as in EAS (Figures $3 b, \mathrm{~d}, \mathrm{f}, \mathrm{h}$ ); this is consistent with the previous studies (e.g. Sillmann et al., 2013b).

The ensemble means of MRI-AGCM20 projections are within the 10th-90th percentile range of the CMIP5 projections over EAS. In contrast, over JPN the MRI-AGCM20 mean lies outside the CMIP5 range in some cases, such as $\triangle \mathrm{Pav}$ and $\triangle \mathrm{Rx} 1 \mathrm{~d}$ in JJA under RCP8.5 (Figures $3 \mathrm{~g}, \mathrm{~h}$ ) and those in September-November (SON) under RCP2.6 (Figures 3e, f). Of note, these remarkable differences between the ensembles of CMIP5 and MRI-AGCM20 are reduced when TC-associated precipitation is excluded. For instance, TC exclusion raises the rate of increase by about 10 (5) points for Rx1d (Pav) in JJA under RCP8.5. This is because TC-associated precipitation acts to reduce the climatological-mean Rx1d due to a significant future decrease in TC frequency over the western North Pacific, although it acts to increase rare extreme precipitation events (i.e. event once in 10 years) due to intensifications of extreme TCs (Kitoh and Endo, 2016, 2019).

In the following sections, focusing on the source of the uncertainty in the future changes of temperature and precipitation over JPN, we will indicate how their uncertainty relates to atmospheric circulation at a large scale, mainly based on the CMIP5 MME.

\section{Future change in mean regional sea-level pressure patterns}

In order to investigate the geographical distribution of future change in seasonal mean atmospheric circulation, Figure 4 illustrates the distribution of future change in SLP pattern, as well as the change in precipitation, for the CMIP5 MME mean under RCP8.5. In December-February (DJF), the positive $\triangle$ SLP in the southeast of JPN weakens the typical winter pattern (Figure 4a; Kimoto, 2005). The Aleutian Low deepens and causes the westerly-wind trends (hereafter simply expressed as westerly trends) north of JPN. These $\triangle$ SLPs are derived from the El Niño-like SST change pattern and partially from the weakened surfacewarming contrast between continents and oceans (Gan et al., 2017). Precipitation decreases over an area from the south of JPN to the southern East Asian land mass, coincident with the location of positive $\triangle$ SLP. In MAM, the negative $\triangle$ SLP to the north of JPN still deepens the Aleutian Low (Figure $4 b$ ), giving strengthened westerly winds and a delayed seasonal march from winter to summer in northern JPN. The high $\triangle$ SLP in the south of JPN also contributes to the increased westerly wind over JPN. In JJA, $\triangle$ SLP corresponds to the weakening of the present-day northward expansion of the summer Pacific High over JPN; that is, the negative $\triangle$ SLP in the north of JPN (Figure 4c) and a more westerly wind over JPN. This $\triangle$ SLP pattern is similar to the 
(a) DJF

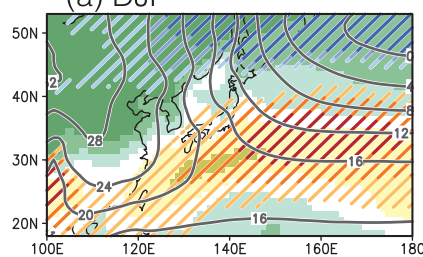

(c) JJA

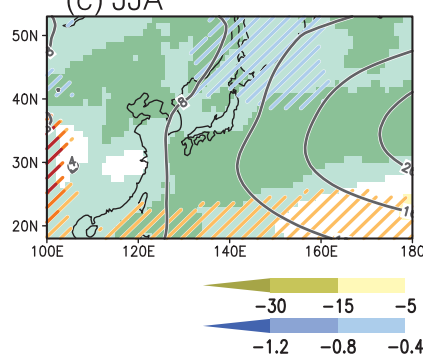

(b) MAM

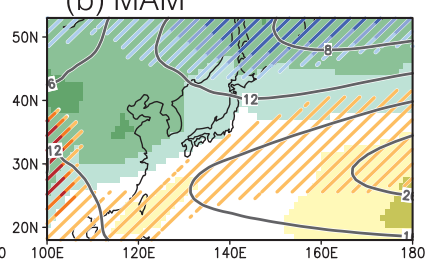

(d) SON

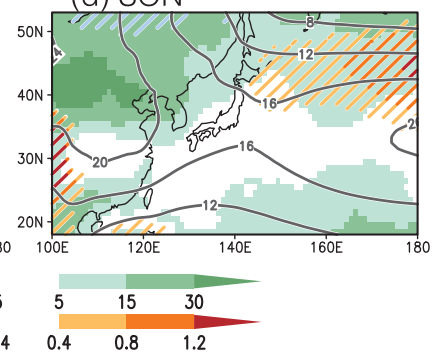

Figure 4. Future changes in precipitation (\%) and sea-level pressure (SLP; $\mathrm{hPa}$ ) for the ensemble mean of the CMIP5 models under the RCP8.5 scenario. Yellow-green shading indicates the precipitation change and blue-red hatching the SLP change. Black contours show the present-day SLP relative to $1000 \mathrm{hPa}$

primary mode in Ose et al. (2020). The increase in precipitation is clear over all of the JPN area. In SON, the presentday Aleutian Low is weakened by the future northward shift of the Pacific High (Figure 4d), giving a southerly change and a delayed seasonal march from summer to winter over JPN (Figure 4d). Note that the regions of positive $\triangle$ SLP and drier climate do not necessarily clearly coincide in all seasons except for DJF.

\section{Inter-model relationship between future JPN climate change and regional circulation}

We investigated the influence of regional atmospheric circulation on future temperature and precipitation over JPN. Figure 5 shows a scatter plot of the seasonal sea-level wind change projected by each model and the ensemble means under RCP8.5. The $x$-axis and $y$-axis denote the indices of $\Delta \mathrm{V}_{\text {index }}$ and $\Delta \mathrm{U}_{\text {index }}$, defined using $\triangle \mathrm{SLP}$ over $25^{\circ} \mathrm{N}-45^{\circ} \mathrm{N}$ and $120^{\circ} \mathrm{E}-150^{\circ} \mathrm{E}$, respectively. Specifically, the distance and the relative position from the origin in Figure 5 represent the magnitude of wind change and the location of positive $\triangle$ SLP around JPN, respectively.

In DJF, 30 of the ensemble models project a southwesterly change (Figure 5a). Namely, positive $\triangle$ SLP is located around the southeast of JPN, as shown in Figure 4a. There is relatively large uncertainly in wind changes for JJA with a spread over all directions, although a westerly change is projected on average (Figure 5c). In MAM and SON, more than $80 \%$ of all CMIP5 models project westerly and southerly changes, respectively (Figures 5b, d), as in Figure $4 \mathrm{~b}$ and Figure 4d. The MRI-AGCM20 mean and uncertainty are mostly located within the inter-model spread of CMIP5 MME for both the wind direction and magnitude.

To explore the model dependence of the future changes in temperature and precipitation (Figures 2, 3) on the regional circulation changes (Figure 5), the inter-model correlations between the changes in each index and the
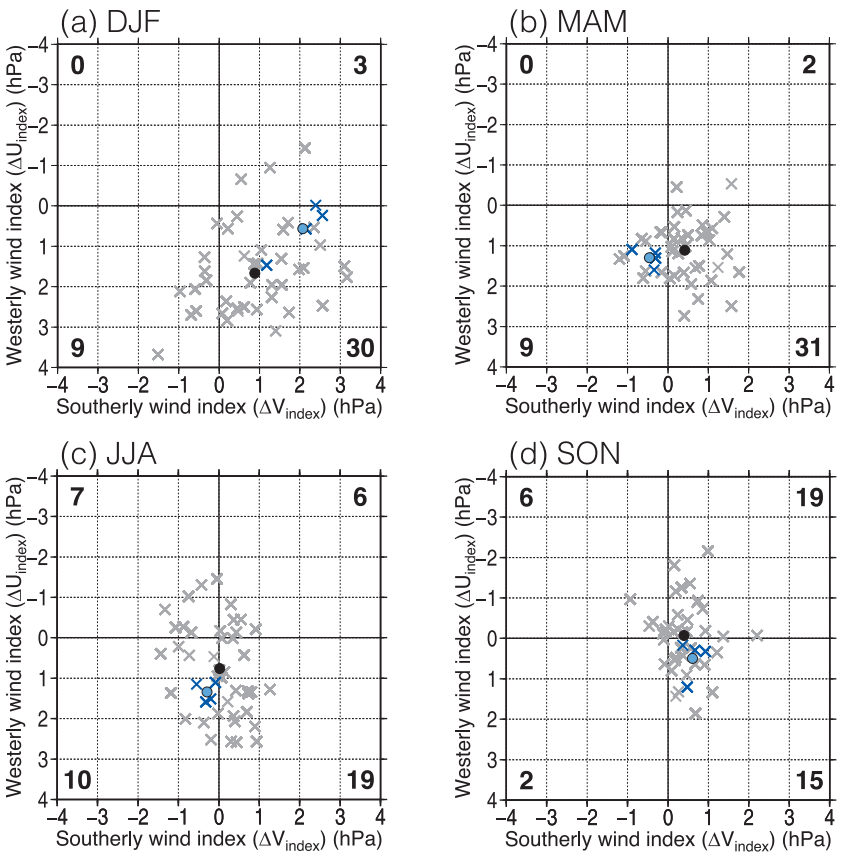

Figure 5. Scatter plot of $\Delta \mathrm{V}_{\text {index }}$ (horizontal axis) and $\Delta \mathrm{U}_{\text {index }}$ (vertical axis) using SLP data around JPN under RCP8.5. Solid circles indicate the MME means and crosses indicate each member of the CMIP5 (black/gray) and MRIAGCM20 (blue) projections. The numbers in the corners are the numbers of CMIP5 models included in each quadrant

wind changes in JPN were computed using the CMIP5 projections; eight wind directions were represented by $\Delta \mathrm{U}_{\text {index }}$, $\Delta \mathrm{V}_{\text {index }}$, and their sum and difference. We summarize the highest correlations among the eight wind directions in Table I.

All seasonal values of $\Delta \mathrm{Tav}$ and $\Delta \mathrm{Pav}$ showed a statistically significant correlation with the wind change at the $95 \%$ level or above. The wind direction indicating the strongest correlation with $\Delta \mathrm{Tav}$ corresponds to the direction of the largest gradient in the present-day surface air temperature climatology around JPN for each season (not shown) and was similar to that for $\triangle \mathrm{SU}$. Over JPN in DJF, the larger the model projection of the southerly anomaly that relates to the strengthening of the positive $\triangle \mathrm{SLP}$ in the east of Japan (Figure S3b), the greater the future temperature increase. In JJA, the larger the model projection of the westerly anomaly that relates to the further strengthening of the Pacific High in the south of JPN (Figure S3c), the greater the advection over JPN of the hot air originating from the continental land to the west of JPN.

The most strongly correlated wind direction was south or southeast, for both $\Delta \mathrm{Pav}$ and $\Delta \mathrm{Rx} 1 \mathrm{~d}$ in nearly all seasons (Table I). The strongest correlation was found in DJF. The DJF projections of the eastward shift of positive $\triangle$ SLP can be explained by the eastward shift of the area of less precipitation and the consequent increase in precipitation over JPN (Figure 4a). In JJA, the enhanced southerly wind leads to a large increase in precipitation over JPN, probably because the southerly or southeasterly anomaly promotes moist air advection over JPN from the relatively warm southern or southeastern sea region during JJA. This is the 
Table I. Largest correlation coefficient between future changes in each index and surface wind among eight wind directions (see text for details)

\begin{tabular}{|c|c|c|c|c|}
\hline & $\begin{array}{l}\text { Mean temperature increase } \\
(\Delta \mathrm{Tav})\end{array}$ & $\begin{array}{l}\text { Summer days increase } \\
(\Delta \mathrm{SU})\end{array}$ & $\begin{array}{l}\text { Mean precipitation increase } \\
(\triangle \mathrm{Pav})\end{array}$ & $\begin{array}{l}\text { Max. 1-day precipitation increase } \\
(\Delta \operatorname{Rx} 1 \mathrm{~d})\end{array}$ \\
\hline DJF & $\begin{array}{l}\text { Southerly } \\
0.57 * * *\end{array}$ & $\begin{array}{l}\text { Southerly } \\
0.22\end{array}$ & $\begin{array}{l}\text { Southerly } \\
0.60^{* * *}\end{array}$ & $\begin{array}{l}\text { Southeasterly } \\
0.55^{* * *}\end{array}$ \\
\hline MAM & $\begin{array}{l}\text { Southwesterly } \\
0.60 * * *\end{array}$ & $\begin{array}{l}\text { Southerly } \\
0.26^{*}\end{array}$ & $\begin{array}{l}\text { Southerly } \\
0.38^{* *}\end{array}$ & $\begin{array}{l}\text { Southerly } \\
0.24\end{array}$ \\
\hline JJA & $\begin{array}{l}\text { Westerly } \\
0.43^{* * *}\end{array}$ & $\begin{array}{l}\text { Westerly } \\
0.44^{* * *}\end{array}$ & $\begin{array}{l}\text { Southeasterly } \\
0.39 * * *\end{array}$ & $\begin{array}{l}\text { Southeasterly } \\
0.50^{* * *}\end{array}$ \\
\hline SON & $\begin{array}{l}\text { Southeasterly } \\
0.59 * * *\end{array}$ & $\begin{array}{l}\text { Southerly } \\
0.35^{* *}\end{array}$ & $\begin{array}{l}\text { Southerly } \\
0.32 * *\end{array}$ & $\begin{array}{l}\text { Easterly } \\
0.40^{* * *}\end{array}$ \\
\hline
\end{tabular}

$* * * 99 \%$ confidence level

$* * 95 \%$ confidence level

$* 90 \%$ confidence level

same for all seasons. The other wind directions indicating the second-highest significant correlation are within a deviation of $45^{\circ}$ from the direction indicating the highest correlation.

The correlation coefficient for $\Delta$ Tav was small in JJA. The strongest correlation, however, exceeded 0.5 in June and July (Table SII). The correlated direction was westerly in June and southerly in July and August. Thus, at least during JJA, discussions based on monthly data are needed to understand more detailed characteristics.

\section{Consistency with the MRI-AGCM20 projections}

Figure 5a shows that, compared with the CMIP5 MME mean, the MRI-AGCM20 mean shows a relatively large southerly trend in DJF, consistent with the positive $\triangle$ SLP being located east of its position in the CMIP5 MME mean (Figure S4a). The positive correlation in the CMIP5 MME between the southerly anomaly and $\triangle$ Tav over JPN (Table I) is consistent with a larger $\Delta \mathrm{Tav}$ in MRI-AGCM20 (Figure 2d). This is the case for the projections of a larger $\triangle$ Pav in MRI-AGCM20, because the southerly anomaly relates to wetter future change in the CMIP5 MME during DJF (Figure 3g).

By the same token, the MRI-AGCM20 projections show larger $\Delta \mathrm{Tav}$ and smaller $\triangle \mathrm{Pav}$ in JJA and larger $\Delta \mathrm{Pav}$ in SON. These are also consistent with the relationship in the CMIP5 MME, indicating that the relatively large westnorthwesterly anomaly in JJA is related to a warmer and drier climate change and the large southerly anomaly in SON is related to a wetter change. The difference in the wind change between the two ensembles seems too small to explain the smaller (larger) trend of $\triangle \mathrm{Pav}$ in JJA (SON), but may explain the reduced difference of $\Delta \mathrm{Pav}$ after excluding the TC-associated precipitation (Figure 3g).

\section{SUMMARY}

This study has clarified that the uncertainty in future climate changes over Japan is significantly related to atmospheric circulation changes around Japan across all seasons, after having confirmed that Japan's climate changes are some- what different from those over the East Asian land region.

Future projections of the CMIP5 MME and the MRIAGCM20 ensemble show a smaller warming rate over JPN than over EAS in all seasons, reflecting the fact that continental land warms faster than the sea surrounding JPN under enhanced greenhouse conditions. Changes in mean precipitation are generally smaller over JPN than over EAS, while the seasonal maximum of 1-day precipitation total increases by a similar rate. However, the quantitative changes of future precipitation depend on the ensembles.

The CMIP5 MME projections using SLP data indicate a weakening of the typical winter pressure pattern over JPN in DJF. Inter-model correlations suggest that a larger southerly-wind anomaly tends to be associated with warmer and wetter future change than in the ensemble mean. In JJA, a weakened northward expansion of the Pacific High is projected over JPN. The models projecting a large westerly-wind anomaly tend to have a hotter summer, implying that a strengthened westerly anomaly caused by the enhanced Pacific High in the south of JPN carries warmer air from the continental land to JPN. An increase in future JJA precipitation is significantly related to the southerly-wind anomaly, implying that there is an enhanced moist air advection from the warm southern sea region. The seasonal march during MAM and SON in the north of JPN tend to be delayed with a future strengthened Aleutian Low and the northward shift of the Pacific High, respectively.

There are some differences in future climate change over JPN between the MRI-AGCM20 ensemble and the CMIP5 MME. They can be roughly explained by differences in large-scale atmospheric circulation changes between the ensembles. In addition to this factor, our results indicate that TC simulations play a significant role in future precipitation changes in MRI-AGCM20. This suggests that typhoon simulations can substantially influence future projections, and, thus, that the CMIP5 models, most of which cannot realistically resolve TCs due to their coarse horizontal resolution, may have some systematic bias in their future projections. Enhancement of model resolution to tens of kilometers or better is one of the key approaches to better project future climate changes specific to Japan. Future improvement and verification of TC simulations 
are expected, including through better understanding of coupling with the ocean.

\section{ACKNOWLEDGMENTS}

This work was conducted under the TOUGOU Program of the MEXT, Japan (JPMXD0717935561) and under the ERTD Fund of the ERCA of Japan (ERTDF 2-1904).

\section{SUPPLEMENTS}

Text $\mathrm{S} 1$. Relationship between wind change indices $\left(\Delta \mathrm{U}_{\text {index }}\right.$ and $\left.\Delta \mathrm{V}_{\text {index }}\right)$ and sea-level geostrophic wind changes

Figure S1. Mean temperature change in EAS and JPN under the RCP2.6 and RCP8.5 scenarios

Figure S2. Same as Figure S1, but for mean precipitation and annual or seasonal maximum of 1-day precipitation total

Figure S3. Geographical distribution of the correlation coefficient between the wind change index and future change in sea-level pressure

Figure S4. Future changes in precipitation and sea-level pressure for the ensemble mean of MRI-AGCM20

Table SI. List of the CMIP5 models analyzed

Table SII. Largest correlation coefficient between future monthly changes in each index and surface wind among eight wind directions for June-September

\section{REFERENCES}

Endo H, Kitoh A. 2014. Thermodynamic and dynamic effects on regional monsoon rainfall changes in a warmer climate. Geophysical Research Letters 41: 1704-1711. DOI: 10.1002/ 2013GL059158.

Endo H, Kitoh A, Mizuta R, Ishii M. 2017. Future changes in precipitation extremes in East Asia and their uncertainty based on large ensemble simulations with a high-resolution AGCM. SOLA 13: 7-12. DOI: 10.2151/sola.2017-002.

Gan B, Wu L, Jia F, Li S, Cai W, Nakamura H, Alexander MA, Miller AJ. 2017. On the response of the Aleutian Low to greenhouse warming. Journal of Climate 30: 3907-3925. DOI: 10.1175/JCLI-D-15-0789.1.

He C, Zhou T. 2015. Responses of the western North Pacific subtropical high to global warming under RCP4.5 and RCP8.5 scenarios projected by 33 CMIP5 models: The dominance of tropical Indian Ocean-tropical western Pacific SST gradient. Journal of Climate 28: 365-380. DOI: 10.1175/JCLID-13-00494.1.

Horinouchi T, Matsumura S, Ose T, Takayabu YN. 2019. Jetprecipitation relation and future change of the Mei-Yu-Baiu rainband and subtropical jet in CMIP5 coupled GCM simulations. Journal of Climate 32: 2247-2259. DOI: 10.1175/ JCLI-D-18-0426.1.

Intergovernmental Panel on Climate Change (IPCC). 2012. Managing the risks of extreme events and disasters to advance climate change adaptation. A special report of Working Groups I and II of the Intergovernmental Panel on Climate Change, Cambridge University Press, Cambridge, UK; 582.

Intergovernmental Panel on Climate Change (IPCC). 2013: Cli- mate change 2013: The physical science basis. Contribution of Working Group I to the fifth assessment report of the Intergovernmental Panel on Climate Change. Cambridge University Press, Cambridge, UK; 1535.

Kimoto M. 2005. Simulated change of the east Asian circulation under global warming scenario. Geophysical Research Letters 32: 1-5. DOI: 10.1029/2005GL023383.

Kitoh A, Endo H. 2016. Future changes in rainfall extremes associated with El Niño projected by a global $20-\mathrm{km}$ mesh atmospheric model. SOLA 12A: 1-6. DOI: 10.2151/sola.12A-001.

Kitoh A, Endo H. 2019. Future changes in precipitation extremes associated with tropical cyclones projected by largeensemble simulations. Journal of the Meteorological Society of Japan Ser. II 97: 141-152. DOI: 10.2151/jmsj.2019-007.

Knutti R, Furrer R, Tebaldi C, Cermak J, Meehl GA. 2010. Challenges in combining projections from multiple climate models. Journal of Climate 23: 2739-2758. DOI: 10.1175/ 2009JCLI3361.1.

Mizuta R, Yoshimura H, Murakami H, Matsueda M, Endo H, Ose T, Kamiguchi K, Hosaka M, Sugi M, Yukimoto S, Kusunoki S, Kitoh A. 2012. Climate simulations using MRIAGCM3.2 with 20-km grid. Journal of the Meteorological Society of Japan 90A: 233-258. DOI: 10.2151/jmsj.2012-A12.

Mizuta R, Arakawa O, Ose T, Kusunoki S, Endo H, Kitoh A. 2014. Classification of CMIP5 future climate responses by the tropical sea surface temperature changes. SOLA 10: 167171. DOI: 10.2151/sola.2014-035.

Ogata T, Ueda H, Inoue T, Hayasaki M, Yoshida A, Watanabe S, Kira M, Ooshiro M, Kumai A. 2014. Projected future changes in the Asian monsoon: A comparison of CMIP3 and CMIP5 model results. Journal of the Meteorological Society of Japan Ser II 92: 207-225. DOI: 10.2151/jmsj.2014-302.

Ose T. 2019. Future changes in summertime East Asian monthly precipitation in CMIP5 and their dependence on present-day model climatology. Journal of the Meteorological Society of Japan Ser II 97: 1041-1053. DOI: 10.2151/jmsj.2019-055.

Ose T, Takaya Y, Maeda S, Nakaegawa T. 2020. Resolution of summertime East Asian pressure pattern and southerly monsoon wind in CMIP5 multi-model future projections. Journal of the Meteorological Society of Japan Ser II 98: 153. DOI: $10.2151 / \mathrm{jmsj} .2020-047$.

Sillmann J, Kharin VV, Zhang X, Zwiers FW, Bronaugh D. 2013a. Climate extremes indices in the CMIP5 multimodel ensemble: Part 1. Model evaluation in the present climate. Journal of Geophysical Research: Atmospheres 118: 17161733. DOI: 10.1002 /jgrd.50203.

Sillmann J, Kharin VV, Zwiers FW, Zhang X, Bronaugh D. 2013b. Climate extremes indices in the CMIP5 multimodel ensemble: Part 2. Future climate projections. Journal of Geophysical Research: Atmospheres 118: 2473-2493. DOI: 10.1002/jgrd.50188.

Taylor KE, Stouffer RJ, Meehl GA. 2012. An overview of CMIP5 and the experiment design. Bulletin of the American Meteorological Society 93: 485-498. DOI: 10.1175/BAMSD-11-00094.1.

Xie SP, Deser C, Vecchi GA, Collins M, Delworth TL, Hall A, Hawkins E, Johnson NC, Cassou C, Giannini A, Watanabe M. 2015. Towards predictive understanding of regional climate change. Nature Climate Change 5: 921-930. DOI: 10.1038/nclimate2689.

Yoshida K, Sugi M, Mizuta R, Murakami H, Ishii M. 2017. Future changes in tropical cyclone activity in high-resolution largeensemble simulations. Geophysical Research Letters 44: 9910-9917. DOI: 10.1002/2017GL075058. 